\title{
Liver ailments in pregnancy: our experience
}

\section{Uttara Aiyer Kohli*, Atul Seth, Sanjay Singh, Rajesh Mishra}

Department of Obstetrics and Gynecology, Armed Forces Medical College, Pune, Maharashtra, India

Received: 20 December 2016

Accepted: 31 January 2017

\section{*Correspondence:}

Dr. Uttara Aiyer Kohli,

E-mail: uttara.aiyer@gmail.com

Copyright: () the author(s), publisher and licensee Medip Academy. This is an open-access article distributed under the terms of the Creative Commons Attribution Non-Commercial License, which permits unrestricted non-commercial use, distribution, and reproduction in any medium, provided the original work is properly cited.

\section{ABSTRACT}

Background: The spectrum of liver disease is varied and is associated with increased maternal and perinatal morbidity and mortality when pregnancy coexists with the liver disease. This study aims to analyze the incidence, spectrum, clinical presentation and outcome of liver diseases complicating pregnancy

Methods: A retrospective cohort study was conducted and data was collected from the hospital records of obstetric cases diagnosed with liver disease complicating pregnancy in a tertiary care hospital, over a period of two years.

Results: A total 146 cases of liver diseases complicating pregnancies were recorded out of 5018 deliveries $(2.9 \%)$. Intrahepatic cholestasis of pregnancy $(n=52,35.62 \%)$ and severe preeclampsia $(n=47,32.19 \%$, with HELLP $n=8$, $5.48 \%)$ accounted for majority of cases. The incidence of chronic hepatitis B infection was $20.56 \%(n=30)$. There were two maternal deaths $(1.37 \%)$ attributed to severe post-partum HELLP and severe preeclampsia with multi organ failure.

Conclusions: Liver diseases in pregnancy have a non-specific presentation and may be associated with a wide range of conditions, early diagnosis and timely appropriate intervention can help reduce the mortality and morbidity.

Keywords: AFLP, HELLP, Liver, Preeclampsia, Pregnancy

\section{INTRODUCTION}

The spectrum of liver disease in pregnancy is varied. Non-specific symptoms at presentation like vomiting, nausea and pain abdomen increase the likelihood of delay in diagnosis in the absence of strong clinical suspicion. Physiological changes of pregnancy do not affect the liver transaminases, serum bilirubin and prothrombin time and these can serve as markers of disease. Liver diseases complicating pregnancy are associated with an increased risk of maternal and perinatal mortality and morbidity.Timely intervention and termination of the pregnancy in cases of liver diseases attributable to pregnancy forms the main stay of treatment.

The incidence of abnormal liver function in pregnancy varies from $3-5 \% .^{1}$ Preeclampsia, HELLP syndrome and IHCP account for the majority of cases of liver dysfunction in later pregnancy. Maternal mortality may be as high as $18 \%$ in cases of acute fatty liver of pregnancy. $^{2}$

Fulminant hepatic failure secondary to acute viral hepatitis in pregnancy is also associated with high maternal mortality. A geographical variation in severity of Hepatitis E has also been reported. ${ }^{3}$

It was thus decided to carry out a retrospective study and analyse the incidence, spectrum, clinical presentation and outcome of liver diseases complicating pregnancy in our institution.

\section{METHODS}

This was a retrospective cohort study which was carried out in a tertiary care hospital of Western India. Hospital 
records of obstetric patients admitted to this hospital from July 2014 to June 2016 were analyzed and data was collected from those with a diagnosis of any liver diseases complicating pregnancy. The study was cleared by the institutional ethical committee.

Diagnosis was based on clinical presentation and altered liver function tests detected during antenatal and immediate postpartum period. The following are the criteria used for diagnosis of these diseases in our institution.

\section{Intra hepatic cholestasis of pregnancy (IHCP)}

IHCP is diagnosed on clinical findings of pruritis especially of palms and soles with or without liver function derangement in the absence of another dermatological or liver disease.

\section{Severe preeclampsia}

Severe preeclamsia was diagnosed on clinical features of pre-eclampsia (hypertension and proteinuria) and any associated feature of severity or complication i.e. presence of fetal growth restriction, abruption, eclampsia, deranged liver (AST >40IU/L) or renal function tests.

\section{Severe preeclampsia with HELLP syndrome/HELLP syndrome}

Diagnosed based on the platelet count $\left(<1,50,000 / \mathrm{mm}^{3}\right)$, LDH (>600IU/L) and Liver enzymes (AST >40IU/L), as partial or complete.

\section{Chronic hepatitis B infection}

Antenatal diagnoses of $\mathrm{HBs} \mathrm{Ag}$ positivity.

\section{Acute viral hepatitis}

Clinical features of hepatitis (anorexia, malaise, jaundice), elevated liver enzymes not attributable to pregnancy related causes and viral markers positive for hepatitis A or E.

\section{Acute fatty liver of pregnancy}

Diagnosed by a strong clinical suspicion, and laboratory findings of elevated aminotransferases and some of the other findings e.g. elevated alkaline phosphatase, leukocytosis, thrombocytopenia, disseminated intravascular coagulopathy (DIC), abnormal prothrombin time, partial thromboplastin time, abnormal fibrinogen, ketonuria, proteinuria, low serum albumin, hypoglycemia, elevated uric acid and ammonia levels.

The data was statistically analysed for incidence of liver diseases, the spectrum and presentation of liver diseases in the study group. Maternal and neonatal outcome in these patients were also noted.

\section{RESULTS}

A total of 5018 patients delivered in the hospital during the study period of 2 years. Of these 146 patients were identified with some form of liver disease complicating pregnancy making the incidence of liver disease $2.9 \%$. Of these affected cases $111(2.2 \%)$ were attributable to liver disease specific to pregnancy.

Table 1: Demographic profile.

\begin{tabular}{|lll|}
\hline Age & $\begin{array}{l}\text { Number of } \\
\text { cases }\end{array}$ & $\begin{array}{l}\text { Percentage (\%) } \\
\text { Total cases n=146 }\end{array}$ \\
\hline$<20$ & 02 & 1.36 \\
\hline $20-25$ & 56 & 38.37 \\
\hline $26-30$ & 64 & 43.83 \\
\hline $31-35$ & 22 & 15.07 \\
\hline $36-40$ & 02 & 1.36 \\
\hline Gravidity & & \\
\hline G1 & 63 & 43.15 \\
\hline G2 & 43 & 29.45 \\
\hline G3 & 29 & 19.86 \\
\hline G4 or more & 11 & 07.53 \\
\hline Period of gestation & 91 & 62.33 \\
\hline $37-40$ & 49 & 33.56 \\
\hline $24-36 w 6 d$ & 06 & 04.11 \\
\hline 22-23w6d* & 02 & \\
\hline
\end{tabular}

*Pregnancy terminated due to severe disease.

Maximum cases were primigravida $43.1 \% \quad(n=63)$ followed by second gravid $29.4 \% \quad(n=43)$ (Table 1). $43.8 \%(n=64)$ were in the age group $26-30$ and $38.3 \%$ $(n=56)$ were $20-25$ years. $62.3 \%(n=91)$ were 37 weeks period of gestation at the time of delivery.

Table 2: Spectrum of liver disease.

\begin{tabular}{|lll|}
\hline Disease & $\begin{array}{l}\text { Number } \\
\text { of cases }\end{array}$ & $\begin{array}{l}\text { Percentage } \\
\text { (total cases } \\
\text { n=146) }\end{array}$ \\
\hline $\begin{array}{l}\text { Intra hepatic cholestasis of } \\
\text { pregnancy IHCP }\end{array}$ & 52 & 35.62 \\
\hline Severe preeclampsia & 47 & 32.19 \\
\hline $\begin{array}{l}\text { Severe preeclampsia with } \\
\text { HELLP syndrome }\end{array}$ & 08 & 05.48 \\
\hline HELLP syndrome & 02 & 01.37 \\
\hline $\begin{array}{l}\text { Chronic hepatitis B } \\
\text { infection }\end{array}$ & 30 & 20.56 \\
\hline Acute viral hepatitis & 03 & 02.05 \\
\hline $\begin{array}{l}\text { Acute Fatty liver of } \\
\text { pregnancy }\end{array}$ & 02 & 01.37 \\
\hline Gilberts syndrome & 01 & 0.68 \\
\hline $\begin{array}{l}\text { Non cirrhotic portal } \\
\text { fibrosis }\end{array}$ & 01 & 0.68 \\
\hline
\end{tabular}

Intrahepatic cholestasis of pregnancy (IHCP) was the most common liver disease recorded $35.6 \% \quad(n=52)$, 
followed by severe preeclampsia $32.1 \% \quad(n=47)$ and chronic hepatitis B infection $20.5 \% \quad(n=30)$. Severe preeclampsia with HELLP accounted for $5.4 \% \quad(n=8)$. There were $2(1.3 \%)$ cases of severe HELLP, one of which was postpartum HELLP without any preeclampsia and resulted in mortality. 2 cases $(1.3 \%)$ had Acute fatty liver of pregnancy (AFLP) and $3(2.0 \%)$ had acute viral hepatitis at the time of delivery as per the records (Table 2 ). Those who had uncomplicated viral hepatitis in the first and second trimester $(n=10)$ are not included in this study as it was a retrospective study from the labour and delivery records and there was insufficient data of such cases. Similarly one case of complicated malaria occurring in the second trimester is also not included. 16 patients $(10.9 \%)$ had jaundice at presentation.

Table 3: Delivery outcome.

\begin{tabular}{|lll|}
\hline Mode of delivery & Number of cases & Percentage \\
\hline Vaginal delivery & 78 & 53.42 \\
\hline Term & 67 & 45.89 \\
\hline Preterm & 11 & 7.53 \\
\hline Caesarean & 60 & 41.10 \\
\hline Term & 22 & 15.07 \\
\hline Preterm & 38 & 26.03 \\
\hline Intrauterine death & 02 & 01.37 \\
\hline Abortions & 06 & 4.11 \\
\hline Hysterotomy & 01 & 0.68 \\
\hline Vaginal & 05 & 3.42 \\
\hline
\end{tabular}

Table 4: Perinatal outcome.

\begin{tabular}{|lll|}
\hline Male & $\begin{array}{l}\text { Number of } \\
\text { cases }\end{array}$ & Percentage \\
\hline Female & 92 & 63.01 \\
\hline Preterm & 54 & 36.99 \\
\hline$\leq 30$ weeks & $\mathbf{4 9}$ & $\mathbf{3 3 . 5 6}$ \\
\hline 31-32 weeks & 5 & 3.42 \\
\hline $33-34$ weeks & 9 & 6.16 \\
\hline 35-36 weeks & 20 & 10.27 \\
\hline Term & $\mathbf{9 1}$ & 13.70 \\
\hline IUD & 02 & $\mathbf{6 2 . 3 3}$ \\
\hline Abortions & 06 & 01.37 \\
\hline Birth weight (Kg) & & 04.11 \\
\hline$<1.5$ & 13 & Total births $\mathbf{n}=\mathbf{1 4 0}$ \\
\hline $1.5-2$ & 14 & 9.29 \\
\hline $2-2.5$ & 28 & 10 \\
\hline $2.5-3$ & 58 & 20 \\
\hline$>3$ & 27 & 41.43 \\
\hline NICU admission & 27 & 19.29 \\
\hline IUGR & 55 & 19.29 \\
\hline IUD & 02 & 39.29 \\
\hline
\end{tabular}

Out of $53.4 \%(n=78)$ cases who delivered vaginally, $45.8 \%$ were term and $7.5 \%$ were preterm (Table 3 ). There were $60(41.1 \%)$ caesareans- $22(15.0 \%)$ term and 38
(26.0\%) preterm caesarean section. $02(1.3 \%)$ patients had intrauterine death-one because of severe preeclampsia and abruption placentae at 33-34 weeks POG and the other because of severe preeclampsia with growth restriction at 34 weeks POG. $06(4.1 \%)$ patients had to undergo induced abortions- due to severe preeclampsia with HELLP in two cases and severe preeclampsia in the remaining four. The average POG was 22-25 weeks at the time of termination of these pregnancies. One patient with severe preeclampsia with deranged biochemical parameters required hysterectomy.

Table 4 shows the perinatal outcome. Of the total 140 births- 138 were live and 2 were stillbirths. There were $49(33.5 \%)$ preterm deliveries out of which $23.9 \%$ were between 33-36 weeks POG. 39.2\% babies had birth weight less than $2.5 \mathrm{~kg}$ and $19.2 \%$ required NICU admission.

Table 5: Maternal complications.

\begin{tabular}{|lll|}
\hline Complication & $\begin{array}{l}\text { Number } \\
\text { of cases }\end{array}$ & $\%$ \\
\hline ICU admission & 15 & 10.27 \\
\hline Preeclampsia/eclampsia & 4 & 2.74 \\
\hline Sepsis & 3 & 2.04 \\
\hline Acute renal failure & 2 & 1.37 \\
\hline Liver failure (sub-acute) & 3 & 2.04 \\
\hline AFLP & 2 & 1.37 \\
\hline Hep E & 1 & 0.68 \\
\hline Multi organ dysfunction & 1 & 0.68 \\
\hline DIC & 2 & 1.37 \\
\hline Postpartum haemorrhage & 40 & 27.40 \\
\hline Coagulopathy & 20 & 13.70 \\
\hline $\begin{array}{l}\text { Blood and blood product } \\
\text { transfusion requirement }\end{array}$ & 30 & 20.55 \\
\hline Mortality & 2 & 1.37 \\
\hline Severe postpartum HELLP & 1 & 0.68 \\
\hline Severe sepsis with MOF & 1 & 0.68 \\
\hline
\end{tabular}

15 patients $(10.2 \%)$ required ICU admission for severe preeclampsia, sepsis, DIC, Liver failure, MOD and ARF (Table 5). Postpartum haemorrhage (27.4\%) and coagulopathy $(13.7 \%)$ were some of the major contributors of maternal morbidity. $20.5 \%$ patients required transfusion of blood and blood products- fresh frozen plasma, platelets, cryoprecipitate. There were two maternal mortalities. One of these was a patient who developed severe postpartum HELLP following an uncomplicated caesarean section. She had severe haemolysis with elevated LDH values (>12000IU). Her liver enzymes were raised (ALT and AST-4500 and 6400IU/L respectively) and platelet count was significantly reduced $(15,000 /$ cumm $)$. She succumbed to multi organ failure inspite of aggressive management, instituted by multidisciplinary team including intensivist and nephrologist. The second mortality was a case of severe preeclampsia and HELLP, who underwent termination of pregnancy at 24 weeks POG. She 
developed complications of acute kidney injury, sepsis and multi organ dysfunction following abortion. There were 2 cases of acute fatty liver of pregnancy who recovered following delivery and supportive care. One patient with viral hepatitis E had subacute liver failure following preterm delivery. However she improved with supportive care in ICU.

\section{DISCUSSION}

Clinical presentation of liver disease in pregnancy varies from jaundice and fulminant hepatic failure to pruritis or mild derangement of liver functions.

The prevalence of liver diseases in pregnancy in our study was $2.9 \%$ of which $0.32 \%$ presented with Jaundice. Liver dysfunction was seen in $3 \%$ of deliveries during a 15 month prospective study from South Wales by Ch'ng et al. ${ }^{4}$ Studies from different parts of India also report incidences ranging from $0.4 \%-3.3 \%$. In a retrospective study from Northern India D'Souza et al reported an overall incidence of $3.3 \% .^{5}$ Sharma et al reported an incidence of $1.9 \%$ of liver disease in pregnancy from Central India. ${ }^{6}$ The incidence of jaundice in pregnancy was reported as $0.4 \%$ by Acharya et al and $0.9 \%$ by Rathi et al. ${ }^{7,8}$

Primigravidas and patients aged 20-30 years accounted for most cases. This was similar to the findings of other studies from India. ${ }^{4-8}$ This is explained as this is the most common age group for pregnancies in India.

Intrahepatic cholestasis of pregnancy IHCP accounted for most of the cases of pregnancy related liver disorders $35.6 \%$ (overall incidence $1.03 \%$ comparable to South Asia statistics of $0.8-1.4 \%$ ). This was similar to that reported by D'Souza et al but more than the other studies as the criteria for diagnosis in our institute is clinical with or without derangement in the liver function tests. ${ }^{5}$ Owing to increased risk of fetal complications with IHCP, American College of Gastroenterology (ACG) guidelines recommend early delivery at 37 weeks. ${ }^{1}$ The outcome of patients with IHCP was good with no perinatal death reported as our institute follows the above guidelines and induces delivery at 37 weeks in patients diagnosed as IHCP.

Severe preeclampsia was a major contributor $(32.1 \%)$ to liver diseases in our institute and an additional $5.4 \%$ had HELLP. This is consistent with results from other studies. Preeclampsia is a multisystem disorder, and the liver is involved in 20 to $30 \%$ of preeclampsia cases. It is the most common cause of liver dysfunction and hepatic tenderness in pregnancy. ${ }^{9}$ Liver involvement is secondary to vasospasm of the hepatic vascular bed. Aminotransferase levels are usually elevated mildly to up to 10 times normal values and most patients in our study had elevation of aminotransferases to 1.5 to 3 times. Jaundice occurs only occasionally (5\%) and the bilirubin level is usually $<5 \mathrm{mg} / \mathrm{dl}$. In present study the maximum serum bilirubin in preeclampsia cases was $2.4 \mathrm{mg} / \mathrm{dl} .08$ patients had preeclampsia complicated by HELLP syndrome and 02 had HELLP syndrome without preeclampsia. Complications requiring ICU admissions were also high in this subset of patients with one maternal mortality.

Incidence of acute fatty liver was $1.3 \%$. This higher incidence as compared to other studies may be due to this center being a referral hospital. Though both patients required ICU admission there was no mortality due to timely delivery and intensive supportive therapy.

Complicated viral hepatitis $\mathrm{E}$ was also a cause of ICU admission however the incidence in our studies $(2.0 \%)$ was lower as compared to other studies, probably due to higher incidence of this disease in northern India. ${ }^{5-8}$ The maternal fetal outcome was good in our patients, as compared to other studies. One reason for this is that present study population had less unbooked cases. The lower incidence may also be explained as we have not included those who had uncomplicated viral hepatitis complicating pregnancy in second trimester.

Differentiating between AFLP and viral hepatitis is important as the decision to deliver defers in both cases. A high index of clinical suspicion and laboratory criteria including Swansea criteria can help in clinching the diagnosis.

$20 \%$ patients had chronic hepatitis B infection and this was the greatest contributor to liver diseases not unique to pregnancy. Patients with high viral load were started on antiviral drugs like lamivudine and telbivudine. All newborns were given Hepatitis B immunoglobulin and HBV vaccination. No patient in present study had acute hepatitis B.

Postpartum hemorrhage and coagulopathy were significant complications leading to increased incidence of blood transfusions in these patients.

There was an increased incidence of preterm deliveries and low birth weight babies as compared to the rest of the population which may be attributed to increased inductions in these patients especially those with severe preeclampsia.

\section{CONCLUSION}

Liver diseases in pregnancy have a non-specific presentation and may be associated with a wide range of conditions, early diagnosis and timely appropriate intervention can help reduce the mortality and morbidity. A team approach and joint management with the gastroenterologist and critical care specialist can improve outcomes. Prospective studies where liver function tests have been done on the slightest suspicion have shown a higher incidence of liver dysfunction in pregnancy as compared to retrospective studies. ${ }^{4}$ Incidence of clinical 
jaundice is low. Hence a high index of suspicion based on subtle signs and symptoms should encourage liver function tests. Institutional deliveries in tertiary care centres for patients with liver disease can improve both maternal and foetal outcome.

Funding: No funding sources

Conflict of interest: None declared

Ethical approval: The study was approved by the Institutional Ethics Committee

\section{REFERENCES}

1. Tran TT, Ahn J, Reau NS. ACG clinical guideline: liver disease and pregnancy. Am J Gastroenterol. 2016 ;111:176-94.

2. Pandey CK, Karna ST, Pandey VK, Tandon M. Acute liver failure in pregnancy: challenges and management. Indian J Anaesthesia. 2015;59(3):1449.

3. Sahai S, Kiran R. Acute Liver Failure in Pregnancy: causative and prognostic factors. Saudi J Gastroenterol. 2015;21(1):30-4.

4. Ch'ng CL, Morgan M, Hainsworth I, Kingham JG. Prospective study of liver dysfunction in pregnancy in Southwest Wales. Gut. 2002;51:876-80.
5. Dsouza AS, Gupta G, Katumalla FS, Goyal S. Maternal and fetal outcome in liver diseases of pregnancy- A tertiary hospital experience. Int J Sci Res Pub. 2015;5(9):1-4.

6. Sharma S, Aherwar R, Jawade S. Maternal and fetal outcome in jaundice complicating pregnancy: a prospective study. Int J Reprod Contracept Obstet Gynecol. 2016;5:1084-7.

7. Acharya N, Acharya S, Shukla S, Athvale R, Shaveta. Study of Jaundice in Pregnancy. Glb J Med Res. 2013;13:25-9.

8. Rathi U, Bapat M, Rathi P, Abraham P. Effect of liver disease on maternal and fetal outcome in pregnancy- a prospective study. Indian J Gastroenterol. 2007;26; 59-63.

9. Hay JE. Liver disease in pregnancy. Hepatology. 2008;47:1067-76.

Cite this article as: Kohli UA, Seth A, Singh S, Mishra R. Liver ailments in pregnancy: our experience. Int J Reprod Contracept Obstet Gynecol 2017;6:939-43. 